\title{
Burden of potentially pathologic copy number variants is higher in children with isolated congenital heart disease and significantly impairs covariate-adjusted transplant-free survival
}

\author{
Daniel Seung Kim, BS, ${ }^{\mathrm{a}, \mathrm{b}, \mathrm{c}}$ Jerry H. Kim, MD, MPH, ${ }^{\mathrm{d}}$ Amber A. Burt, MS, ${ }^{\mathrm{a}}$ David R. Crosslin, PhD, ${ }^{\mathrm{a}, \mathrm{b}}$ \\ Nancy Burnham, MSN, ${ }^{e}$ Cecilia E. Kim, BS, ${ }^{\mathrm{f}}$ Donna M. McDonald-McGinn, MS, ${ }^{g}$ Elaine H. Zackai, MD, ${ }^{g}$ \\ Susan C. Nicolson, MD, ${ }^{\text {h }}$ Thomas L. Spray, MD, ${ }^{\mathrm{e}}$ Ian B. Stanaway, BS, ${ }^{\mathrm{b}}$ Deborah A. Nickerson, PhD, \\ Patrick J. Heagerty, PhD, ${ }^{\mathrm{c}}$ Hakon Hakonarson, MD, PhD, ${ }^{\mathrm{f}} \mathrm{J}$. William Gaynor, MD, ${ }^{\mathrm{e}}$ and \\ Gail P. Jarvik, MD, $\mathrm{PhD}^{\mathrm{a}, \mathrm{b}}$
}

\section{ABSTRACT}

Objectives: Copy number variants $(\mathrm{CNVs})$ are duplications or deletions of genomic regions. Large CNVs are potentially pathogenic and are overrepresented in children with congenital heart disease (CHD). We sought to determine the frequency of large CNVs in children with isolated CHD, and to evaluate the relationship of these potentially pathogenic CNVs with transplant-free survival.

Methods: These cases are derived from a prospective cohort of patients with nonsyndromic CHD $(n=422)$ identified before first surgery. Healthy pediatric controls $(n=500)$ were obtained from the electronic Medical Records and Genetic Epidemiology Network, and CNV frequency was contrasted for CHD cases and controls. CNVs were determined algorithmically; subsequently screened for $>95 \%$ overlap between 2 methods, size ( $>300 \mathrm{~kb})$, quality score, overlap with a gene, and novelty (absent from databases of known, benign CNVs); and separately validated by quantitative polymerase chain reaction. Survival likelihoods for cases were calculated using Cox proportional hazards modeling to evaluate the joint effect of $\mathrm{CNV}$ burden and known confounders on transplant-free survival.

Results: Children with nonsyndromic CHD had a higher burden of potentially pathogenic CNVs compared with pediatric controls $(12.1 \%$ vs $5.0 \%$; $P=.00016)$. Presence of a CNV was associated with significantly decreased transplant-free survival after surgery (hazard ratio, 3.42; 95\% confidence interval, 1.66-7.09; $P=.00090$ ) with confounder adjustment.

Conclusions: We confirm that children with isolated $\mathrm{CHD}$ have a greater burden of rare/large CNVs. We report a novel finding that these CNVs are associated with an adjusted 2.55-fold increased risk of death or transplant. These data suggest that CNV burden is an important modifier of survival after surgery for CHD. (J Thorac Cardiovasc Surg 2016;151:1147-51)

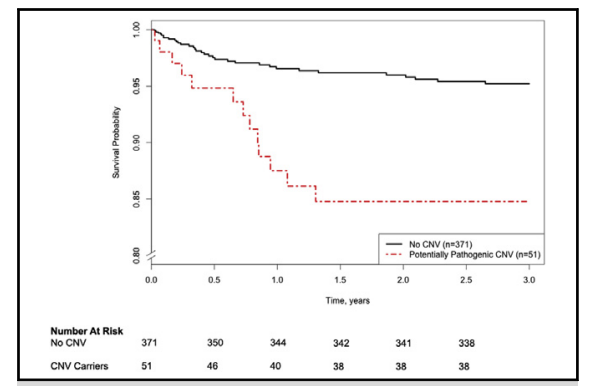

Covariate-adjusted transplant-free survival by potentially pathogenic CNV in CHD cases.

Central Message

Isolated CHD cases have greater CNV burden. We also report a novel finding that CNVs are associated with an increased risk of death.

\section{Perspective}

Large genomic copy number variants (CNVs) are rare and potentially pathogenic. We found that children with isolated congenital CHD have a greater burden of large/rare CNVs, and that these CNVs are associated with an increased risk of death. These data suggest that $\mathrm{CNV}$ burden is an important modifier of survival after surgery for CHD and has the potential for use in risk stratification.

See Editorial Commentary page 1152.
From the ${ }^{\mathrm{a}}$ Division of Medical Genetics, Department of Medicine, Departments of
${ }^{\mathrm{b}}$ Genome Sciences, ${ }^{\mathrm{c}}$ Biostatistics and ${ }^{\mathrm{d}}$ Anesthesiology and Pain Medicine,
University of Washington, Seattle, Wash and the Divisions of ${ }^{\mathrm{e}}$ Cardiothoracic
Surgery, ${ }^{\mathrm{g}}$ Genetics and ${ }^{\mathrm{h}}$ Cardiothoracic Anesthesiology, and ${ }^{\mathrm{f}}$ Center for Applied
Genomics, The Children's Hospital of Philadelphia, Philadelphia, Pa.
This work was supported by a grant from the Fannie E. Rippel Foundation, an
American Heart Association National Grant-in-Aid (9950480N), National
Institutes of Health (NIH) Grant HL071834, and a Washington State Life Sciences
Discovery Award to the Northwest Institute for Genetic Medicine. The Children's
Hospital of Philadelphia site of the eMERGE network was supported by NIH Grant
U01HG006830. DSK was supported by NIH Grants 1F31MH101905-01 and
T32HL007312 and a grant from the American Heart Association Western States Affiliate (16POST27250048).

Read at the 95th Annual Meeting of The American Association for Thoracic Surgery, Seattle, Washington, April 25-29, 2015.

Received for publication April 20, 2015; revisions received Aug 14, 2015; accepted for publication Sept 14, 2015; available ahead of print Dec 15, 2015.

Address for reprints: Gail P. Jarvik, MD, PhD, Medical Genetics, Box 357720, University of Washington, Seattle, WA 98195-7720 (E-mail: pair@u.washington.edu). $0022-5223 / \$ 36.00$

Copyright (C) 2016 by The American Association for Thoracic Surgery

http://dx.doi.org/10.1016/j.jtcvs.2015.09.136 


$$
\begin{aligned}
& \text { Abbreviations and Acronyms } \\
& \begin{aligned}
\text { CHD } & =\text { congenital heart disease } \\
\mathrm{CHOP} & =\text { The Children's Hospital of Philadelphia } \\
\mathrm{CNV} & =\text { copy number variant } \\
\mathrm{CPB} & =\text { cardiopulmonary bypass } \\
\mathrm{DHCA} & =\text { deep hypothermic circulatory arrest } \\
\mathrm{ECMO} & =\text { extracorporeal membrane oxygenation } \\
\text { eMERGE } & \text { electronic Medical Records and } \\
& \text { Genetic Epidemiology } \\
\text { LOS } & =\text { length of stay }
\end{aligned}
\end{aligned}
$$

Supplemental material is available online.

Congenital heart disease (CHD) represents the most common human birth defect, often requiring surgical intervention with cardiopulmonary bypass (CPB) or circulatory arrest soon after birth. Survival after surgery has improved, but long-term mortality remains considerable, particularly for more severe CHDs, including single-ventricle lesions. ${ }^{1}$

Genetic factors, particularly those that are rare and alter proteins, are hypothesized to be major contributors to human disease. ${ }^{2}$ Copy number variants (CNVs), duplicated or deleted regions of the genome, have been reported as potential causes of sporadic CHDs. ${ }^{3,4}$ CNVs are reportedly more frequent in children with CHD compared with controls. ${ }^{5}$ In addition, CNVs larger than $300 \mathrm{~kb}$ and overlapping a gene have been reported to be more frequent in CHD cases and associated with poorer growth and cognitive outcomes. ${ }^{6}$ Of note, previous studies reporting the prevalence of CNVs in children with $\mathrm{CHD}$ have included syndromic patients (eg, those with DiGeorge 22q11.2 microdeletions).

We previously used data from this cohort of children with isolated CHD to demonstrate the strong protective effects of VEGFA and SOD2 genetic variants on transplant-free survival. ${ }^{7}$ Given the protein-disrupting potential of these large, gene-overlapping CNVs, we hypothesize that such CNVs also likely affect survival. Thus, in the present study we sought to determine the frequency of these potentially pathogenic CNVs among children with CHD compared with healthy pediatric controls, and to evaluate whether these large CNVs affect transplant-free survival in the first 3 years of follow-up after surgical correction of CHD.

\section{METHODS}

\section{Ethics Statement}

Between October 1998 and April 2003, subjects were enrolled at The Children's Hospital of Philadelphia (CHOP) on a protocol approved by the Institutional Review Boards of CHOP and the University of
Washington. Informed written consent was obtained from a parent or guardian of each subject.

\section{CHD Case Population}

In this analysis of a previously described prospective cohort of 550 participants enrolled in a prospective study at $\mathrm{CHOP}$ to study neurodevelopmental dysfunction after surgical correction for CHD (hereinafter referred to as the "CHD cases"), ${ }^{8-10}$ patients aged 6 months or younger who underwent $\mathrm{CPB}$ with or without deep hypothermic circulatory arrest (DHCA) for repair of CHD were eligible for enrollment. Exclusion criteria included (1) multiple distinct congenital anomalies, (2) a recognizable genetic or phenotypic syndrome, and (3) a language other than English spoken in the home. Recognition of dysmorphic features can be difficult in neonates, however, and in some patients genetic syndromes were identified at subsequent evaluation, and these subjects were removed from the dataset before analysis.

This study examined a subset of the cohort with genetic data $(n=422)$ to establish the prevalence of large, gene-overlapping CNVs compared with that in healthy pediatric controls, and determine whether these potentially pathogenic CNVs were associated with differential transplant-free survival. We note that no genome-wide association analyses have been attempted using these CNV data; this is solely a study of the global burden of large, gene-overlapping $\mathrm{CNVs}$ and how they affect transplant-free survival in the first 3 years after surgical correction of CHD.

Of the original $550 \mathrm{CHD}$ cases, 73 were excluded owing to the lack of high-quality genotype data, leaving a total of 477 subjects for analysis. An additional 55 subjects were excluded owing to the presence of DiGeorge syndrome or other chromosomal/genetic abnormalities, which would be expected to bias both the estimation of CNV prevalence and the evaluation of the effects of CNVs on survival for CHD, given that patients with genetic syndromes generally have worse survival. ${ }^{11}$ A total of 422 patients were considered after these exclusions. Details of data collection (including further information on inclusion/exclusion criteria), operative management, and genotyping have been reported previously.

\section{Control Population}

Healthy control subjects (hereinafter referred to as "controls") from the same site (CHOP) for comparisons of CNV prevalence were obtained from the Electronic Medical Records and Genetic Epidemiology (eMERGE) consortium. ${ }^{12}$ A total of 500 healthy controls without CHD or other conditions associated with increased CNV prevalence (eg, autism, schizophrenia) were analyzed for the presence of large, gene-overlapping CNVs.

\section{Genetic Evaluation to Exclude Subjects With Syndromic CHD}

CHD cases were evaluated by a genetic dysmorphologist at the 1-year and/or 4-year examinations. Patients were classified as having no indication of genetic syndrome or chromosomal abnormality (normal, isolated CHD), suspected genetic syndrome (suspect), or a definite genetic syndrome or chromosomal abnormality (genetic). Following this classification, each CHD case's genetic record was reviewed by a second senior board-certified medical geneticist, blinded to the genetic data, to determine whether to include or exclude the subject from the current analysis, which focuses on nonsyndromic subjects. Based on this review, 55 CHD cases with a known or suspected genetic syndrome were excluded from our analysis owing to the potential for genetic confounding effects on $\mathrm{CNV}$ prevalence and the resulting effect on transplant-free survival within the first 3 years of follow-up after surgery.

\section{Genotyping}

Whole blood or buccal swab samples were obtained before surgery in CHD case subjects and at study enrollment in controls, and stored at 
$4{ }^{\circ} \mathrm{C}$. Genomic DNA was isolated from white blood cells and genotyping was performed at CHOP's Center for Applied Genomics.

\section{CNV Determination and Validation}

CNVs were determined algorithmically with Illumina HumanHap 550k BeadChip data for the CHD cases and Illumina 610k-Quad BeadChip data for the controls using the programs PennCNV ${ }^{13}$ and GWASTools. ${ }^{14}$ In brief, CNVs were considered potentially pathogenic after filtering for size ( $>300 \mathrm{~kb})$, PennCNV quality score $>100$, overlap with genes, and novelty, as reported previously. ${ }^{6}$ Novelty was determined by comparing the called CNVs to the Database of Genomic Variants (http://projects. tcag.ca/variation/). CNVs were filtered from the data if $>50 \%$ of the CNV overlapped with another nonpathogenic CNV already cataloged in the Database of Genomic Variants. CNVs identified as pathogenic and present in the Database of Genomic Variants were not filtered from the data. To prevent false-positive CNV calls from algorithmic methods, we filtered all CNVs for a minimum of $95 \%$ overlap in calls from the PennCNV and GWASTools programs. The foregoing methods were applied separately for the CHD cases and controls. A complete list of the CNVs determined algorithmically for both the CHD cases and controls is provided in Table E1.

CNVs were validated by quantitative polymerase chain reaction (qPCR) at CHOP's Center for Applied Genomics. Of the 38 tested CNVs from the CHD cases with available DNA, in 2 samples CNVs failed to validate (ie, showed the reference copy number) and 1 sample failed to undergo DNA amplification (likely owing to poor DNA quality) and thus could not be tested for CNV. Excluding the DNA quality-related qPCR failure, 35 of 37 predicted CNVs were successfully validated, for a validation rate of $94.6 \%$ (Table E1). Information on qPCR primers information for the 38 tested CNVs is provided in Table E2.

\section{Statistical Analyses}

All analyses and graphics were performed in R (http://www.r-project. org/) using standard regression packages. The $\chi^{2}$ test was used to test the significance of the difference in frequency of large, gene-overlapping CNVs between the CHD cases and controls.

Genetic ancestry was determined as described previously. ${ }^{15}$ Owing to the mixed ancestry of the cohort, the first 3 principal component eigenvectors were used as covariates in Cox proportional hazards regression models, to adjust for potential population stratification. ${ }^{16}$

In CHD cases, time to long-term mortality was calculated from the date of initial surgery to the date of death. A Cox proportional hazards model was used to evaluate the joint effect of the global burden of potentially pathogenic CNVs and covariates affecting survival. Output from this model was used in plotting survival curves. Survival analyses were adjusted for the previously reported confounding variables: the first 3 principal component eigenvectors for race, gestational age, birth weight, diagnostic class (coded as a dummy variable with diagnostic class 1 as the reference group), ${ }^{17}$ total surgical support time (ie, total minutes on either CPB or DHCA), and extracorporeal membrane oxygenation (ECMO) use. Diagnosis class was assigned based on preoperative diagnosis according to a previously proposed scheme ${ }^{17}$ : class I, 2-ventricle heart without arch obstruction; class II, 2-ventricle heart with arch obstruction; class III, single-ventricle heart without arch obstruction; and class IV, singleventricle heart with arch obstruction. Confidence intervals (CIs) and 2-sided $P$ values were calculated based on an asymptotic normal distribution of the estimated hazard ratio (HR) using Wald statistics.

\section{RESULTS}

Baseline characteristics of the studied subset of the CHD cases stratified by presence or absence of a potentially pathogenic CNV are presented in Table 1. Compared with
TABLE 1. Baseline characteristics of the CHD cases, stratified by the presence or absence of potentially pathogenic $\mathrm{CNV}$

\begin{tabular}{|c|c|c|c|c|}
\hline Characteristic & $\begin{array}{l}\text { No CNV } \\
(n=371)\end{array}$ & $\begin{array}{c}\text { CNV } \\
(\mathbf{n}=\mathbf{5 1})\end{array}$ & $\begin{array}{l}\text { Combined } \\
(n=422)\end{array}$ & $\begin{array}{c}P \\
\text { value }\end{array}$ \\
\hline Male sex, $\mathrm{n}(\%)$ & $208(56)$ & $37(73)$ & $245(58)$ & $.040 *$ \\
\hline Ethnicity, n (\%) & & & & $.49^{*}$ \\
\hline Caucasian & $240(65)$ & $33(65)$ & $273(65)$ & \\
\hline African & $85(23)$ & $14(27)$ & $99(23)$ & \\
\hline Hispanic & $18(5)$ & $1(2)$ & $19(5)$ & \\
\hline Asian & $12(3)$ & $0(0)$ & $12(3)$ & \\
\hline Native American & $7(2)$ & $2(4)$ & $9(2)$ & \\
\hline Other & $9(2)$ & $1(2)$ & $10(2)$ & \\
\hline $\begin{array}{l}\text { Gestational age, wk, } \\
\text { mean } \pm \mathrm{SD}\end{array}$ & $38.5 \pm 2.0$ & $38.0 \pm 2.1$ & $38.5 \pm 2.1$ & $.062 \dagger$ \\
\hline $\begin{array}{l}\text { Birth weight, } \mathrm{kg} \\
\quad \text { mean } \pm \mathrm{SD}\end{array}$ & $3.16 \pm 0.60$ & $3.03 \pm 0.72$ & $3.15 \pm 0.62$ & $.13 \dagger$ \\
\hline Diagnostic class, n $(\%)$ & & & & $.88^{*}$ \\
\hline Class 1 & $179(48)$ & $25(49)$ & $204(48)$ & \\
\hline Class 2 & $36(10)$ & $5(10)$ & $41(10)$ & \\
\hline Class 3 & $39(11)$ & $7(14)$ & $46(11)$ & \\
\hline Class 4 & $117(32)$ & $14(27)$ & $131(31)$ & \\
\hline $\begin{array}{l}\text { Preoperative LOS, } \mathrm{d}, \\
\text { mean } \pm \mathrm{SD}\end{array}$ & $2.2 \pm 2.6$ & $2.1 \pm 2.7$ & $2.1 \pm 2.6$ & $.57 \dagger$ \\
\hline Intubation, $\mathrm{n}(\%)$ & $104(28)$ & $15(29)$ & $119(28)$ & $.97^{*}$ \\
\hline $\begin{array}{l}\text { Total surgical support } \\
\quad \text { time, min, mean } \pm \mathrm{SD}\end{array}$ & $30 \pm 50$ & $20 \pm 35$ & $29 \pm 48$ & $.22 \dagger$ \\
\hline $\begin{array}{l}\text { Delayed sternal closure, } \\
\mathrm{n}(\%)\end{array}$ & $56(15)$ & $5(10)$ & $61(14)$ & $.48^{*}$ \\
\hline ECMO use, n (\%) & $22(6)$ & $1(2)$ & $23(5)$ & $.40^{*}$ \\
\hline $\begin{array}{l}\text { Postoperative LOS, } \mathrm{d}, \\
\text { mean } \pm \mathrm{SD}\end{array}$ & $16 \pm 23$ & $18 \pm 29$ & $16 \pm 24$ & $.62 \dagger$ \\
\hline Mortality, n (\%) & $34(9)$ & $13(25)$ & $47(11)$ & - \\
\hline
\end{tabular}

CHD cases without a potentially pathogenic CNV, those with a potentially pathogenic $\mathrm{CNV}$ included a significantly higher proportion of males $(73 \%$ vs $56 \% ; P=.040)$ and had a nominally lower gestational age (mean, 38.0 vs 38.5 weeks; $P=.062)$. Birth weight was not significantly different (mean, $3.03 \mathrm{~kg}$ in CHD cases with a qualifying $\mathrm{CNV}$ vs $3.16 \mathrm{~kg}$ in those without; $P=.13$ ). No significant differences between the 2 subgroups were seen in terms of distribution of race/ethnicity (with Europeans composing the majority of the cases, followed by individuals of African ancestry), diagnostic class, preoperative length of stay (LOS), incidence of preoperative intubation, total surgical support time, incidence of delayed sternal closure, ECMO use, and postoperative LOS.

Fifty-one of the $422 \mathrm{CHD}$ cases evaluated $(12.1 \%)$ had a $\mathrm{CNV}$ that exceeded $300 \mathrm{~kb}$, overlapped with a gene, and was novel (ie, potentially pathogenic). In comparison, 25 such potentially pathogenic CNVs were identified in 500 $(5.0 \%)$ of the healthy control cohort (see Table E1 for a list of identified CNVs). Applying the $\chi^{2}$ test revealed a significant difference in the proportion of potentially 
TABLE 2. Association of potentially pathogenic CNV on transplantfree survival in the CHD cases, adjusting for confounders with Cox proportional hazards regression $(n=422$, with 47 deaths or heart transplants observed)

\begin{tabular}{lcc}
\hline \multicolumn{1}{c}{ Covariate } & HR $(\mathbf{9 5} \% \mathbf{C I})$ & $\boldsymbol{P}$ value \\
\hline Gestational age & $0.90(0.80-1.02)$ & .93 \\
Birth weight & $0.99(0.99-1.02)$ & .19 \\
Male sex & $0.84(0.44-1.58)$ & .64 \\
Diagnostic class 2 & $1.19(0.25-5.71)$ & .82 \\
Diagnostic class 3 & $2.77(0.91-8.41)$ & .073 \\
Diagnostic class 4 & $9.70(3.89-24.22)$ & $1.13 \times 10^{-6}$ \\
Total surgical support time & $1.01(1.00-1.02)$ & .037 \\
ECMO use & $14.44(6.73-31.00)$ & $7.42 \times 10^{-12}$ \\
Genetic ancestry PC1 & - & .40 \\
Genetic ancestry PC2 & - & .24 \\
Genetic ancestry PC3 & - & .0086 \\
Potentially pathogenic CNV* & $3.43(1.66-7.09)$ & .0009 \\
\hline$H R$, Hazard ratio; $C I$, confidence interval; ECMO, extracorporeal membrane \\
oxygenation; $P C$, principal component eigenvector (for genetic ancestry adjustment); \\
$C N V$, copy number variant. *Presence of a potentially pathogenic CNV is associated \\
with a 2.1\% increased risk of transplant or death.
\end{tabular}

pathogenic CNVs between the CHD cases and the controls $(12.1 \%$ vs $5.0 \% ; P=.00016)$.

To examine the possible association between the presence of a large, gene-overlapping, novel CNV and transplant-free survival, we applied a Cox proportional hazards model. Survival analyses demonstrated a strong increased risk of death associated with potentially pathogenic CNVs in a model jointly adjusting for the following covariates: the first 3 principal component eigenvectors for race, gestational age, birth weight, sex, diagnostic class, total surgical support time, and ECMO use (HR, 3.43; 95\% CI,1.66-7.09; $P=.0009$ ) (Table 2 and Figure 1). A Cox proportional hazard model $R^{2}$ comparison estimated the effect of $\mathrm{CNV}$ burden on transplant-free survival as $2.1 \%$. Sensitivity analyses of the effect of covariate-adjusted $\mathrm{CNV}$ burden on transplant-free survival across diagnostic classes are presented in Table E3.

\section{DISCUSSION}

Here we confirm previous published reports ${ }^{5,6}$ that large, gene-overlapping, novel $\mathrm{CNVs}$ are present at higher frequency in children with isolated, nonsyndromic CHD compared with controls $(12.1 \%$ vs $5.0 \%)$. CNVs present in a catalog of nonpathogenic CNVs were excluded, because they were less likely to contribute to survival given their known benign status. Note that we computed CNV frequency specifically for participants with isolated CHD not attributed to any known genetic or chromosomal anomaly that could have biased our results. In addition, we report for the first time that large, gene-overlapping, novel CNVs are associated with an estimated 3.43-fold increased risk of death compared with patients without such CNVs (95\% CI, 1.66-7.09; $P=.00009)$. Overall,

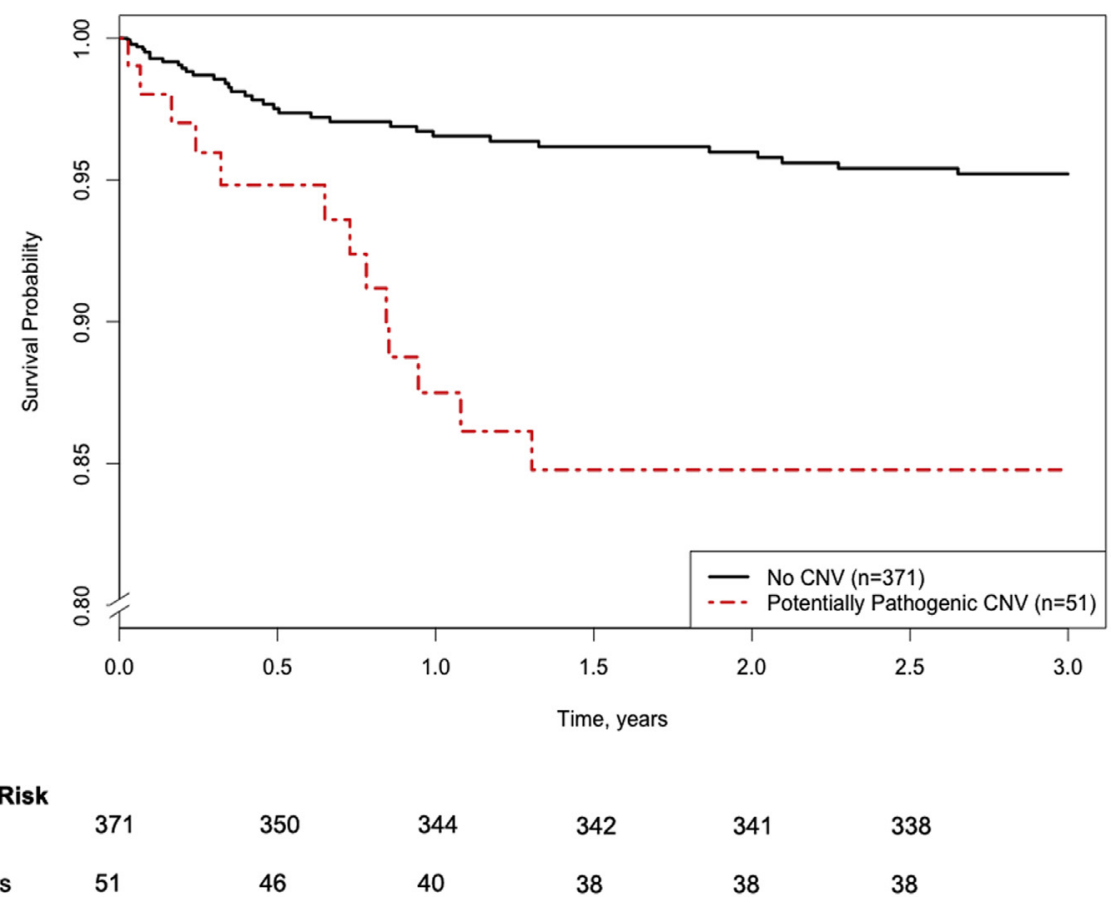

FIGURE 1. Covariate-adjusted long-term survival by the presence of potentially pathogenic CNV in CHD cases ( $\mathrm{n}=422$, with $47 \mathrm{observed} \mathrm{events).} \mathrm{Note}$ the discontinuous $y$-axis, which begins at an adjusted survival probability of 0.8 . The $95 \%$ CIs for covariate-adjusted survival probability are 0.960 to 0.990 , 0.947 to $0.985,0.941$ to $0.982,0.939$ to 0.981 , and 0.931 to 0.978 for the no $\mathrm{CNV}$ group and 0.901 to $0.997,0.798$ to $0.959,0.762$ to $0.943,0.762$ to 0.943 , and 0.762 to 0.943 for the CNV group at $0.5,1,1.5,2$, and 2.5 years of follow-up, respectively. $C N V$, Copy number variant. 
this novel association of large, gene-overlapping CNVs and survival further emphasizes the importance of genetic factors in explaining complex phenotype variation and outcomes.

CNVs, which can result in the duplication or deletion of entire genes (ie, a change in the copy number of a particular gene), are one of several types of mutations currently thought to account for the "missing heritability" of complex genetic traits not yet adequately explained by common genetic variants studied in genome-wide association scans. ${ }^{2}$ In children, $\mathrm{CNV}$ s have been implicated in the pathogenesis of numerous diseases, including schizophrenia ${ }^{18}$ and autism. ${ }^{19} \mathrm{CNV}$ s also have been identified as potential causes of specific CHD diagnoses. ${ }^{3,4}$ In the present study, we have expanded on previous work and herein present evidence that the global burden of large, gene-overlapping CNVs is likely pathogenic, with a significantly increased risk of heart transplant or death after surgery seen in CNV carriers. Of note, analyses in adult cohorts have also identified an association between large CNVs and mortality. ${ }^{20}$

Some limitations of this study should be considered. First, statistical power was limited owing to the size of the CHD case cohort and lack of comparable cohorts. We addressed the rarity of each individual CNV by focusing on the global burden of these large, gene-overlapping, and novel CNVs; however, given this pooling approach to analysis, we were unable to determine whether CNVs in a given region were more responsible than others for the effect on survival. In addition, because of this analytic method, we cannot specifically identify the reason for the impact of CNVs on survival. As noted in Table E1, multiple chromosomal regions are affected, and it is unlikely that a single common pathway is acting to affect survival in these patients. Finally, because we lack genotype data on parents of the affected CHD cases, we are unable to infer whether these rare CNV events are de novo or inherited. De novo variants in affected children of unaffected parents are considered more likely to be pathogenic.

In conclusion, our results confirm that large, geneoverlapping, novel CNVs are enriched in children with isolated CHD compared with healthy children, and provide new evidence that these CNVs are associated with poorer survival. Further follow-up of the pathogenic effects of these potentially pathogenic CNVs in a similar prospective cohort lacking survivor bias is imperative. Given the approximate 3.5-fold enrichment of these pathogenic CNVs in children with isolated CHD, validation of these results could lead to the development of new preventive and risk assessment strategies aimed at decreasing the morbidity and mortality of CHD.

\section{Conflict of Interest Statement}

Authors have nothing to disclose with regard to commercial support.
We thank all of the children and families for their participation.

\section{References}

1. Feinstein JA, Benson DW, Dubin AM, Cohen MS, Maxey DM, Mahle WT, et al Hypoplastic left heart syndrome: current considerations and expectations. J Am Coll Cardiol. 2012;59(1 Suppl):S1-42.

2. Eichler EE, Flint J, Gibson G, Kong A, Leal SM, Moore JH, et al. Missing heritability and strategies for finding the underlying causes of complex disease. Nat Rev Genet. 2010;11:446-50.

3. Hitz MP, Lemieux-Perreault LP, Marshall C, Feroz-Zada Y, Davies R, Yang SW, et al. Rare copy number variants contribute to congenital left-sided heart disease. PLoS Genet. 2012;8:e1002903.

4. Soemedi R, Wilson IJ, Bentham J, Darlay R, Töpf A, Zelenika D, et al. Contribution of global rare copy-number variants to the risk of sporadic congenital heart disease. Am J Hum Genet. 2012;91:489-501.

5. Glessner JT, Bick AG, Ito K, Homsy JG, Rodriguez-Murillo L, Fromer M, et al. Increased frequency of de novo copy number variants in congenital heart disease by integrative analysis of single nucleotide polymorphism array and exome sequence data. Circ Res. 2014;115:884-96.

6. Carey AS, Liang L, Edwards J, Brandt T, Mei H, Sharp AJ, et al. Effect of copy number variants on outcomes for infants with single ventricle heart defects. Circ Cardiovasc Genet. 2013;6:444-51.

7. Kim DS, Kim JH, Burt AA, Crosslin DR, Burnham N, McDonald-McGinn DM, et al. Patient genotypes impact survival after surgery for isolated congenital heart disease. Ann Thorac Surg. 2014;98:104-10.

8. Gaynor JW, Gerdes M, Zackai EH, Bernbaum J, Wernovsky G, Clancy RR, et al. Apolipoprotein E genotype and neurodevelopmental sequelae of infant cardiac surgery. J Thorac Cardiovasc Surg. 2003;126:1736-45.

9. Gaynor JW, Nord AS, Wernovsky G, Bernbaum J, Solot CB, Burnham N, et al. Apolipoprotein E genotype modifies the risk of behavior problems after infant cardiac surgery. Pediatrics. 2009;124:241-50.

10. Kim DS, Stanaway IB, Rajagopalan R, Bernbaum JC, Solot CB, Burnham N, et al Results of genome-wide analyses on neurodevelopmental phenotypes at four-year follow-up following cardiac surgery in infancy. PLoS One. 2012;7:e45936.

11. Kyburz A, Bauersfeld U, Schinzel A, Riegel M, Hug M, Tomaske M, et al. The fate of children with microdeletion 22q11.2 syndrome and congenital heart defect: clinical course and cardiac outcome. Pediatr Cardiol. 2008;29:76-83.

12. Sleiman P, Bradfield J, Mentch F, Almoguera B, Connolly J, Hakonarson H Assessing the functional consequence of loss of function variants using electronic medical record and large-scale genomics consortium efforts. Front Genet. 2014; $5: 105$.

13. Wang K, Li M, Hadley D, Liu R, Glessner J, Grant SF, et al. PennCNV: an integrated hidden Markov model designed for high-resolution copy number variation detection in whole-genome SNP genotyping data. Genome Res. 2007; 17:1665-74.

14. Gogarten SM, Bhangale T, Conomos MP, Laurie CA, McHugh CP, Painter I, et al GWASTools: an R/Bioconductor package for quality control and analysis of genome-wide association studies. Bioinformatics. 2012;28:3329-31.

15. Kosoy R, Nassir R, Tian C, White PA, Butler LM, Silva G, et al. Ancestry informative marker sets for determining continental origin and admixture proportions in common populations in America. Hum Mutat. 2009;30:69-78.

16. Price AL, Patterson NJ, Plenge RM, Weinblatt ME, Shadick NA, Reich D. Principal components analysis corrects for stratification in genome-wide association studies. Nat Genet. 2006;38:904-9.

17. Clancy RR, McGaurn SA, Wernovsky G, Spray TL, Norwood WI, Jacobs ML, et al. Preoperative risk-of-death prediction model in heart surgery with deep hypothermic circulatory arrest in the neonate. I Thorac Cardiovasc Surg. 2000;119:347-57.

18. Walsh T, McClellan JM, McCarthy SE, Addington AM, Pierce SB, Cooper GM, et al. Rare structural variants disrupt multiple genes in neurodevelopmental pathways in schizophrenia. Science. 2008;320:539-43.

19. Girirajan S, Johnson RL, Tassone F, Balciuniene J, Katiyar N, Fox K, et al. Global increases in both common and rare copy number load associated with autism. Hum Mol Genet. 2013;22:2870-80.

20. Kuningas M, Estrada K, Hsu YH, Nandakumar K, Uitterlinden AG, Lunetta KL, et al. Large common deletions associate with mortality at old age. Hum Molec Genet. 2011;20:4290-6.

Key Words: copy number variation, survival, congenital heart disease, genetics 
TABLE E1. qPCR validation of 38 CNVs identified in 38 unique CHD participants with available DNA

\begin{tabular}{|c|c|c|c|c|}
\hline Group & CNV region & Size & CNV type & Validate \\
\hline CHD & chr22:17257787-19792353 & $2,534,566$ & Deletion, 1 copy & 1 \\
\hline CHD & chr22:17257787-19792353 & $2,534,566$ & Deletion, 1 copy & 1 \\
\hline CHD & chr7:4102511-4867717 & 765,206 & Duplication, 1 copy & 1 \\
\hline CHD & $\operatorname{chr} 18: 13417800-15112502$ & $1,694,702$ & Duplication, 1 copy & 1 \\
\hline CHD & chr22:17257787-19792353 & $2,534,566$ & Deletion, 1 copy & 1 \\
\hline CHD & chr22:17257787-19792353 & $2,534,566$ & Deletion, 1 copy & 1 \\
\hline CHD & chr22:17257787-19792353 & $2,534,566$ & Deletion, 1 copy & 1 \\
\hline CHD & chr22:17257787-19792353 & $2,534,566$ & Deletion, 1 copy & 1 \\
\hline CHD & chr15:20306549-20685685 & 379,136 & Deletion, 1 copy & 1 \\
\hline CHD & chr22:21122400-21554058 & 431,658 & Deletion, 1 copy & 1 \\
\hline CHD & chr22:17257787-19792353 & $2,534,566$ & Deletion, 1 copy & 1 \\
\hline CHD & chr15:20306549-20685685 & 379,136 & Deletion, 1 copy & 1 \\
\hline CHD & chr22:21011312-21554058 & 542,746 & Deletion, 1 copy & 1 \\
\hline CHD & chr7:143056311-143505123 & 448,812 & Duplication, 1 copy & 1 \\
\hline CHD & 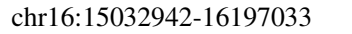 & $1,164,091$ & Duplication, 1 copy & 1 \\
\hline CHD & chr22:17257787-19792353 & $2,534,566$ & Deletion, 1 copy & 1 \\
\hline CHD & chr15:20306549-20685685 & 379,136 & Deletion, 1 copy & 1 \\
\hline CHD & chr15:20306549-20685685 & 379,136 & Deletion, 1 copy & 1 \\
\hline CHD & chr10:133136594-133608348 & 471,754 & Duplication, 1 copy & 1 \\
\hline $\mathrm{CHD}$ & chr10:46410734-47173619 & 762,885 & Duplication, 1 copy & 1 \\
\hline CHD & chr22:17257787-19726528 & $2,468,741$ & Deletion, 1 copy & 1 \\
\hline CHD & chr22:21024486-21441861 & 417,375 & Deletion, 1 copy & 1 \\
\hline CHD & chr22:17257787-19792353 & $2,534,566$ & Deletion, 1 copy & 1 \\
\hline CHD & chr3:95067163-95989113 & 921,950 & Duplication, 1 copy & 1 \\
\hline CHD & chr10:2682656-3123648 & 440,992 & Duplication, 1 copy & 1 \\
\hline CHD & chr1:239320770-240023059 & 702,289 & Duplication, 1 copy & 1 \\
\hline CHD & chr12:33415349-34669982 & $1,254,633$ & Duplication, 1 copy & 1 \\
\hline CHD & chr22:21024486-21554058 & 529,572 & Deletion, 1 copy & 1 \\
\hline CHD & chr13:102725899-103348161 & 622,262 & Duplication, 1 copy & 1 \\
\hline CHD & chr22:17257787-19792353 & $2,534,566$ & Deletion, 1 copy & 1 \\
\hline CHD & chr22:17257787-19790220 & $2,532,433$ & Deletion, 1 copy & 1 \\
\hline CHD & chr22:17257787-19792353 & $2,534,566$ & Deletion, 1 copy & 1 \\
\hline CHD & chr15:20306549-20778963 & 472,414 & Deletion, 1 copy & 1 \\
\hline CHD & chr22:20885078-21401228 & 516,150 & Deletion, 1 copy & 1 \\
\hline CHD & chr22:17257787-18686993 & $1,429,206$ & Deletion, 1 copy & 1 \\
\hline CHD & chr8:11620338-11935618 & 315,280 & Duplication, 1 copy & 0 \\
\hline CHD & chr2:111303487-111617069 & 313,582 & Duplication, 1 copy & 0 \\
\hline CHD & chr9:194201-589666 & 395,465 & Duplication, 1 copy & NA* \\
\hline CHD & chr22:21100917-21554058 & 453,141 & Deletion, 1 copy & - \\
\hline CHD & chr15:20306549-20685685 & 379,136 & Deletion, 1 copy & - \\
\hline CHD & chr6:65228140-66383666 & $1,155,526$ & Deletion, 1 copy & - \\
\hline CHD & chr16:15032942-16197033 & $1,164,091$ & Deletion, 1 copy & - \\
\hline CHD & chr7:158059922-158621330 & 561,408 & Duplication, 1 copy & - \\
\hline CHD & chr7:57212608-57593745 & 381,137 & Duplication, 1 copy & - \\
\hline CHD & chr16:21892987-22331199 & 438,212 & Duplication, 1 copy & - \\
\hline CHD & chr15:20306549-20685685 & 379,136 & Deletion, 1 copy & - \\
\hline CHD & chr22:17257787-19792353 & $2,534,566$ & Deletion, 1 copy & - \\
\hline CHD & chr22:17257787-19792353 & $2,534,566$ & Deletion, 1 copy & - \\
\hline CHD & chr15:20306549-20685684 & 329,335 & Deletion, 1 copy & - \\
\hline CHD & chr22:17257787-19729278 & $2,471,491$ & Deletion, 1 copy & - \\
\hline CHD & chr22:21024486-21554058 & 529,572 & Deletion, 1 copy & - \\
\hline CHD & chr22:17257787-19792353 & $2,534,566$ & Deletion, 1 copy & - \\
\hline CHD & chr22:20784580-21330892 & 546,312 & Deletion, 1 copy & - \\
\hline CHD & chr22:21100917-21554058 & 453,141 & Deletion, 1 copy & - \\
\hline CHD & chr22:17257787-19792353 & $2,534,566$ & Duplication, 1 copy & - \\
\hline
\end{tabular}


TABLE E1. Continued

\begin{tabular}{|c|c|c|c|c|}
\hline Group & CNV region & Size & CNV type & Validate \\
\hline CHD & chr1:244544759-244871447 & 326,688 & Duplication, 1 copy & - \\
\hline CHD & chr3:11622173-11958591 & 336,418 & Duplication, 1 copy & - \\
\hline CHD & chr22:21328337-21979242 & 650,905 & Deletion, 1 copy & - \\
\hline CHD & chr22:17257787-19792353 & $2,534,566$ & Deletion, 1 copy & - \\
\hline CHD & chr22:17257787-19792353 & $2,534,566$ & Deletion, 1 copy & - \\
\hline CHD & chr22:21046568-21401228 & 354,660 & Deletion, 1 copy & - \\
\hline CHD & chr6:162521711-162900893 & 379,182 & Duplication, 1 copy & - \\
\hline $\mathrm{CHD}$ & chr12:24803300-25155526 & 352,226 & Duplication, 1 copy & - \\
\hline CHD & chr15:20306549-20685684 & 329,335 & Duplication, 1 copy & - \\
\hline $\mathrm{CHD}$ & chr22:21328337-21979242 & 650,905 & Deletion, 1 copy & - \\
\hline CHD & chr22:17257787-19792353 & $2,534,566$ & Duplication, 1 copy & 一 \\
\hline CHD & chr22:19066315-19792353 & 726,038 & Duplication, 1 copy & - \\
\hline CHD & chr3:1394026-1975594 & 581,568 & Duplication, 1 copy & - \\
\hline CHD & chr12:33415349-34565140 & $1,149,791$ & Duplication, 1 copy & - \\
\hline CHD & chr22:17257787-19792353 & $2,534,566$ & Deletion, 1 copy & - \\
\hline CHD & chr9:4117491-4537288 & 419,797 & Duplication, 1 copy & - \\
\hline CHD & chr22:17257787-19792353 & $2,534,566$ & Deletion, 1 copy & - \\
\hline CHD & chr3:832325-1403635 & 571,310 & Duplication, 1 copy & - \\
\hline CHD & chr22:17257787-19792353 & $2,534,566$ & Deletion, 1 copy & - \\
\hline CHD & chr9:36587-360439 & 323,852 & Deletion, 1 copy & - \\
\hline CHD & chr3:133579573-133940085 & 360,512 & Deletion, 1 copy & - \\
\hline Control & chr22:19420148-19792353 & 372,205 & Duplication, 1 copy & - \\
\hline Control & chr18:1070791-1767013 & 696,222 & Duplication, 1 copy & - \\
\hline Control & chr4:117695261-118972510 & $1,277,249$ & Deletion, 1 copy & - \\
\hline Control & chr3:2721456-3035501 & 314,045 & Duplication, 1 copy & - \\
\hline Control & chr6:93770526-94218919 & 448,393 & Duplication, 1 copy & - \\
\hline Control & chr8:13592327-14702986 & $1,110,659$ & Duplication, 2 copies & - \\
\hline Control & chr4:189370201-189766567 & 396,366 & Deletion, 1 copy & - \\
\hline Control & chr21:46289633-46909417 & 619,784 & Duplication, 1 copy & - \\
\hline Control & chr21:46192812-46909417 & 716,605 & Duplication, 1 copy & - \\
\hline Control & chr21:46391256-46909417 & 518,161 & Duplication, 1 copy & - \\
\hline Control & chr3:832325-1403635 & 571,310 & Duplication, 1 copy & - \\
\hline Control & chr15:20314760-20635884 & 321,124 & Duplication, 1 copy & - \\
\hline Control & chr21:46086792-46909417 & 822,625 & Duplication, 1 copy & - \\
\hline Control & chr1:246136535-246563486 & 426,951 & Duplication, 1 copy & - \\
\hline Control & chr7:71532565-71921501 & 388,936 & Deletion, 1 copy & - \\
\hline Control & chr15:20321135-20778963 & 457,828 & Deletion, 1 copy & - \\
\hline Control & chr19:47975960-48387680 & 411,720 & Duplication, 1 copy & - \\
\hline Control & chr15:20314760-20635884 & 321,124 & Duplication, 1 copy & - \\
\hline Control & chr2:78591176-79811160 & $1,219,984$ & Deletion, 1 copy & - \\
\hline Control & chr3:540961-1325458 & 784,497 & Duplication, 1 copy & - \\
\hline Control & chr21:46449972-46909417 & 459,445 & Duplication, 1 copy & - \\
\hline Control & chr3:832325-1415351 & 583,026 & Duplication, 1 copy & - \\
\hline Control & chr12:1142624-1461019 & 318,395 & Duplication, 1 copy & - \\
\hline Control & chr15:29807358-30302218 & 494,860 & Duplication, 1 copy & - \\
\hline Control & chr21:20828763-21672012 & 843,249 & Duplication, 1 copy & - \\
\hline
\end{tabular}

Positions based on the hg18 genome build. $C N V$, Copy number variant; $C H D$, congenital heart defect; $q P C R$, quantitative polymerase chain reaction. *Sample failure did not amplify tested CNV regions or control CNV regions, indicating poor DNA quality; denoted by "NA." 
TABLE E2. Primer design for qPCR validation of CNVs in the CHD cohort

\begin{tabular}{|c|c|c|c|c|c|c|}
\hline No. & Targeted region(s) & $\begin{array}{c}\text { Amplicon position } \\
\text { (hg18) }\end{array}$ & Amplicon sequence & UPL probe & $\begin{array}{c}\text { Left primer } \\
\text { sequence }\end{array}$ & $\begin{array}{c}\text { Right primer } \\
\text { sequence }\end{array}$ \\
\hline 1 & $\begin{array}{c}\text { chr1:239320770- } \\
240023059\end{array}$ & $\begin{array}{c}\text { chr1:239824508- } \\
239824631\end{array}$ & $\begin{array}{l}\text { tcacaatgggtctgatctgcatttcacttc } \\
\text { cagctgctggtaggtctttagcaggc } \\
\text { ctctggcacctcagcagtcggaggc } \\
\text { acagaagctgcaaaagggatcttcg } \\
\text { aaactgggcagagaaaaa }\end{array}$ & 11 & tcacaatgggtctgatctgc & tttttctctgcccagtttcg \\
\hline 1 & $\begin{array}{c}\text { chr2:111303487- } \\
111617069\end{array}$ & $\begin{array}{c}\text { chr2:111461205- } \\
111461304\end{array}$ & $\begin{array}{l}\text { aaccactctttggectgctccaaaactg } \\
\text { ggctgaatctgtgggggacaagct } \\
\text { gagaaccaggtacgtattactcag } \\
\text { gccatcatcatctgccttcagtgg }\end{array}$ & 26 & aaccactctttggcetgct & ccactgaaggcagatgatga \\
\hline 1 & $\begin{array}{c}\text { chr3:95067163- } \\
95989113\end{array}$ & $\begin{array}{c}\text { chr3:95285939- } \\
95285998\end{array}$ & $\begin{array}{l}\text { gctcctggagggaaatcaatagctct } \\
\text { gctgcagtgtgcttgtccaggtag } \\
\text { tgtgctttcc }\end{array}$ & 84 & gctcctggagggaaatcaat & ggaaagcacactacctggaca \\
\hline 1 & $\begin{array}{c}\text { chr7:4102511- } \\
4867717\end{array}$ & $\begin{array}{c}\text { chr7:4214233- } \\
4214299\end{array}$ & $\begin{array}{l}\text { ccaacctcttgctgttcctaacagatt } \\
\text { tactactgggaggcagacagc } \\
\text { cagaacgaaacggagaaaa }\end{array}$ & 16 & ccaacctcttgetgttcctaa & ttttctccgtttcgttctgg \\
\hline 1 & $\begin{array}{l}\text { chr7:143056311- } \\
143505123\end{array}$ & $\begin{array}{l}\text { chr7:143297051- } \\
143297125\end{array}$ & $\begin{array}{r}\text { caaacttctctgcttcactcttgtgtcc } \\
\text { cagcagtcagagggaacccttta } \\
\text { aaatataactcagctttgggaggc }\end{array}$ & 3 & caaacttctctgcttcactcttgt & gcctcccaaagctgagttatatt \\
\hline 1 & $\begin{array}{c}\text { chr8:11620338- } \\
11935618\end{array}$ & $\begin{array}{c}\text { chr8:11748292- } \\
11748409\end{array}$ & $\begin{array}{l}\text { cgacaggggatggaaagagggcct } \\
\text { gctccgggcattggccaacacca } \\
\text { gcaggcagcagagggaggccc } \\
\text { agagctgccacatgttggaagcc } \\
\text { ggatcctagatccacctggaga } \\
\text { ggaca }\end{array}$ & 27 & cgacaggggatggaaagag & tgtcctctccaggtggatct \\
\hline 1 & $\begin{array}{c}\text { chr9:194201- } \\
589666\end{array}$ & $\begin{array}{c}\text { chr9:460625- } \\
460697\end{array}$ & $\begin{array}{l}\text { caagaaagcaccgccactccagtg } \\
\text { ggaacggacacgcgtgcacac } \\
\text { agccacgagtgaggtttgaaag } \\
\text { aggccc }\end{array}$ & 76 & caagaaagcaccgccact & gggcctctttcaaacctcac \\
\hline 1 & $\begin{array}{l}\text { chr10:2682656- } \\
\quad 3123648\end{array}$ & $\begin{array}{l}\text { chr10:2822646- } \\
\quad 2822705\end{array}$ & $\begin{array}{l}\text { cccgctcctctgatttactgtgaatc } \\
\text { ctggctgtgtgcagatgatggc } \\
\text { tgagagcaaagg }\end{array}$ & 76 & cccgctcetctgatttactg & cctttgctctcagccatcat \\
\hline 1 & $\begin{array}{l}\text { chr10:46410734- } \\
\quad 47173619\end{array}$ & $\begin{array}{l}\text { chr10:47128596- } \\
\quad 47128719\end{array}$ & $\begin{array}{l}\text { ggtaccatggacctgactggag } \\
\text { aatatttcaccgectggccetg } \\
\text { ggctccaggagagcccacca } \\
\text { ccaccatggcccaggatgga } \\
\text { ggcagcactggcgccaggg } \\
\text { gcaagcaggtcacagatgcca }\end{array}$ & 58 & ggtaccatggacctgactgg & tggcatctgtgacctgctt \\
\hline 1 & $\begin{array}{c}\text { chr10:133136594- } \\
133608348\end{array}$ & $\begin{array}{c}\text { chr10:133261877- } \\
133261938\end{array}$ & $\begin{array}{l}\text { cttggtaaccgecagacgggat } \\
\text { cccatccagccattcagctg } \\
\text { ccatcctgggaaagggagac }\end{array}$ & 42 & cttggtaaccgccagacg & gtctccetttcccaggatg \\
\hline 1 & $\begin{array}{l}\text { chr12:33415349- } \\
34669982\end{array}$ & $\begin{array}{l}\text { chr12:33644954- } \\
33645013\end{array}$ & $\begin{array}{l}\text { aatccccaggacggtgtttgtact } \\
\text { tggggagcagccttagtagca } \\
\text { gcaagccactgagtg }\end{array}$ & 32 & aatccccaggacggtgtt & cactcagtggcttgctgcta \\
\hline 1 & $\begin{array}{c}\text { chr13:102725899- } \\
103348161\end{array}$ & $\begin{array}{c}\text { chr13:102965076- } \\
102965136\end{array}$ & $\begin{array}{l}\text { tcacctatccetggtgcattaggc } \\
\text { ttttaaactctgccttcaggttg } \\
\text { attgggaattgcat }\end{array}$ & 13 & tcacctatccetggtgcatt & atgcaattcccaatcaacct \\
\hline 5 & $\begin{array}{l}\text { chr15:20306549- } \\
20685685\end{array}$ & $\begin{array}{l}\text { chr15:20415639- } \\
\text { 20415748 }\end{array}$ & $\begin{array}{l}\text { acttgcaagctatgaggaattttt } \\
\text { tcttaatggaaggaggagat } \\
\text { accatgtatgacttctacacg } \\
\text { tcaatttttgataaaataagag } \\
\text { aaaaggaaacatggcagaatgtg }\end{array}$ & 12 & acttgcaagctatgaggaattttt & cacattctgccatgtttcett \\
\hline 1 & $\begin{array}{l}\text { chr16:15032942- } \\
\quad 16197033\end{array}$ & $\begin{array}{l}\text { chr16:16045782- } \\
\quad 16045846\end{array}$ & $\begin{array}{l}\text { aacggcttcacctccttgtgttcc } \\
\text { aggcagccggtgaaggttg } \\
\text { tgtactcctccaaggatcctgc }\end{array}$ & 27 & aacggettcacctccttgt & gcaggatcettggaggagta \\
\hline
\end{tabular}


TABLE E2. Continued

\begin{tabular}{|c|c|c|c|c|c|c|}
\hline No. & Targeted region(s) & $\begin{array}{c}\text { Amplicon position } \\
\text { (hg18) }\end{array}$ & Amplicon sequence & UPL probe & $\begin{array}{c}\text { Left primer } \\
\text { sequence }\end{array}$ & $\begin{array}{c}\text { Right primer } \\
\text { sequence }\end{array}$ \\
\hline 1 & $\begin{array}{l}\text { chr18:13417800- } \\
\quad 15112502\end{array}$ & $\begin{array}{l}\text { chr18:13731942- } \\
13732020\end{array}$ & $\begin{array}{l}\text { caggcacagagatgaacca } \\
\text { gctgtcatgagagtgata } \\
\text { cctacttccagcttaatttt } \\
\text { attggtgtgactgttggtgatc }\end{array}$ & 11 & caggcacagagatgaaccag & gatcaccaacagtcacaccaa \\
\hline 14 & $\begin{array}{l}\text { chr22:17257787- } \\
19792353, \\
\text { chr22:17257787- } \\
19726528, \\
\text { chr22:17257787- } \\
19790220, \\
\text { chr22:17257787- } \\
18686993\end{array}$ & $\begin{array}{l}\text { chr22:17729380- } \\
17729493\end{array}$ & $\begin{array}{l}\text { ttctcatcgetgtcactgctgc } \\
\text { tctccaggaggtctcggg } \\
\text { gcctcagctctttcacaag } \\
\text { gttctgctcttttaacctgc } \\
\text { acaaaaacattacatcac } \\
\text { acttccttcagaaacc }\end{array}$ & 79 & ttctcatcgetgtcactgct & ggtttctgaagggaagtgtga \\
\hline \multirow[t]{3}{*}{5} & $\begin{array}{l}\text { chr22:20885078- } \\
\text { 21401228, } \\
\text { chr22:21011312- } \\
21554058, \\
\text { chr22:21024486- } \\
\text { 21441861, } \\
\text { chr22:21024486- } \\
\text { 21554058, } \\
\text { chr22:21122400- } \\
21554058\end{array}$ & $\begin{array}{l}\text { chr22:21222566- } \\
\quad 21222627\end{array}$ & $\begin{array}{l}\text { cgagcacctctactggaatgaagggc } \\
\text { tgctctgcctctgtgctcaaaccatct } \\
\text { acttttcgc }\end{array}$ & 13 & cgagcacctctactggaatga & gcgaaaagtagatggtttgagc \\
\hline & $\begin{array}{l}\text { SNCA positive } \\
\quad \text { control }\end{array}$ & $\begin{array}{c}\text { chr4:90962489- } \\
90962560\end{array}$ & $\begin{array}{l}\text { gctgagaagaccaaagag } \\
\text { caagtgacaaatgttgga } \\
\text { ggagcagtggtgacggg } \\
\text { tgtgacagcagtagcccag }\end{array}$ & 68 & gctgagaagaccaaagagcaa & ctgggctactgctgtcacac \\
\hline & $\begin{array}{l}\text { GAPDH positive } \\
\quad \text { control }\end{array}$ & $\begin{array}{l}\text { chr12:6515824- } \\
\quad 6515886\end{array}$ & $\begin{array}{l}\text { gctgcattcgccctcttaatgg } \\
\text { ggaggtggectagggctg } \\
\text { ctcacatattctggaggagectc }\end{array}$ & 10 & gctgcattcgccetctta & gaggctcctccagaatatgtga \\
\hline
\end{tabular}

TABLE E3. Sensitivity analyses from Cox proportional hazards regression by diagnostic class for the outcome of covariate-adjusted transplant-free survival

\begin{tabular}{lcccc}
\hline $\begin{array}{l}\text { Diagnostic } \\
\text { class }\end{array}$ & Total & Events & $\begin{array}{c}\text { CNV burden, } \\
\text { HR (95\% CI) }\end{array}$ & $\begin{array}{c}\boldsymbol{P} \\
\text { value }\end{array}$ \\
\hline 1 & 204 & 9 & $16.54(1.71-159.80)$ & .015 \\
2 & 41 & 2 & $60.47\left(0.15-2.45 \times 10^{9}\right)$ & .646 \\
3 & 46 & 5 & $6.64(0.51-86.33)$ & .148 \\
4 & 131 & 31 & $2.47(9.67-6.31)$ & .059 \\
\hline
\end{tabular}

Cox proportional hazards regression analyses reported adjusted for all variables reported in the Statistical Analyses section with the exception of diagnostic class (which was singular in each sensitivity analysis). $C N V$, Copy number variant; $H R$, hazard ratio; $C I$, confidence interval. 